\title{
Механизмы институционализации и имплементации концепции «умный регион» в управлении устойчивым пространственным развитием территорий
}

\author{
Лыщикова Ю.В. \\ Белгородский государственный национальный исследовательский университет, \\ Россия, 308015, г. Белгород, ул. Победы, 85 \\ E-mail: lyshchikova@bsu.edu.ru
}

\begin{abstract}
Аннотация. Реализация национального проекта «Цифровая экономика», перманентные реформы государственного управления диктуют требования к поиску новой модели устойчивого пространственного развития на основе комплексного внедрения цифровых технологий во все сферы функционирования экономики и общества. Данные изменения уже активно происходят в большом числе регионов, однако существует разрозненность цифровых инициатив в регионах наряду с дублированием и пересечением региональных и федеральных проектов. В то же время в ряде регионов накоплен необходимый человеческий потенциал и уровень развития цифровых и инновационных технологий, чтобы обеспечить максимальный социально-экономический и управленческий синергетический эффект от внедрения новых управленческих концепций и моделей. Цель исследования - разработка механизмов институционализации и имплементации концепции «Умный регион» в управлении устойчивым пространственным развитием регионов России на основе оценки человеческого капитала в контексте цифровизации и «умной специализации». В статье в результате анализа основных индексов оценки человеческого капитала, цифровизации стран и регионов, научных публикаций по данной тематике, на основе концепции комбинированной стоимости и соответствующей ей методологии отбора показателей IRIS сформирована совокупность показателей оценки цифровизации человеческого капитала регионов РФ. Проведена оценка и кластеризация регионов РФ по сформированным группам показателей и выявлены их пространственные особенности и «цифровые разрывы». По результатам оценки и кластеризации сформирована система критериальных признаков для проведения типологии регионов России согласно приоритетным направлениям «умной специализации» и развитию человеческого капитала в целях внедрения концепции «Умный регион», представленная в виде управленческой матрицы. В завершение исследования разработан алгоритм внедрения концепции «Умный регион» в управление устойчивым пространственным развитием территорий, включающий необходимые этапы реализации, инструментарий и последовательность процедур. Для обеспечения перехода к перспективной специализации предложено использование механизмов воспроизводства человеческого капитала региона в контексте цифровизации и «умной» специализации» на основе «умного» пространственного бенчмаркинга и направлений импакт-инвестирования.
\end{abstract}

Ключевые слова: устойчивое пространственное развитие, «умный регион», «умная специализация», человеческий капитал, цифровизация, концепция комбинированной стоимости, импактинвестирование.

Благодарности: статья подготовлена при финансовой поддержке Гранта Президента РФ, номер проекта - МК-23.2019.6, тема проекта ««Умный регион» как междисциплинарный концепт устойчивого пространственного развития».

Для цитирования: Лыщикова Ю.В. 2021. Механизмы институционализации и имплементации концепции «умный регион» в управлении устойчивым пространственным развитием территорий. Экономика. Информатика, 48(2): 229-243. DOI 10.52575/2687-0932-2021-48-2-229-243. 


\title{
Mechanisms of institutionalization and implementation of the concept of "Smart Region" in the management of sustainable spatial development of territories
}

\author{
Julia V. Lyshchikova \\ Belgorod National Research University \\ 85 Pobeda St, Belgorod, 308015, Russia
}

\begin{abstract}
The implementation of the national project "Digital Economy", permanent reforms of public administration dictate the requirements for the search for a new model of sustainable spatial development based on the integrated implementation of digital technologies in all areas of the functioning of the economy and society. These changes are already actively taking place in a large number of regions, but there is a fragmentation of digital initiatives in the regions, along with duplication and overlap of regional and federal projects. At the same time, several regions have accumulated the necessary human potential and the level of development of digital and innovative technologies to ensure the maximum socio-economic and managerial synergy effect from the introduction of new management concepts and models. The aim of the study is to develop mechanisms for institutionalization and implementation of the concept of "Smart Region" in the management of sustainable spatial development of Russian regions based on the assessment of human capital in the context of digitalization and "smart specialization". In the article, as a result of the analysis of the main indices of human capital assessment, digitalization of countries and regions, scientific publications on this topic, on the basis of the concept of combined value and the corresponding methodology for selecting IRIS indicators, a set of indicators for assessing the digitalization of human capital in the regions of the Russian Federation is formed. The assessment and clustering of the regions of the Russian Federation according to the formed groups of indicators is carried out and their spatial features and "digital gaps" are revealed. Based on the results of the assessment and clustering, a system of criteria for the typology of Russian regions was formed in accordance with the priority areas of "smart specialization" and human capital development in order to implement the concept of "Smart Region", presented in the form of a management matrix. At the end of the study, an algorithm for implementing the concept of "Smart Region" in the management of sustainable spatial development of territories, including the necessary implementation stages, tools and sequence of procedures, was developed. To ensure the transition to a promising specialization, it is proposed to use the mechanisms of reproduction of the region's human capital in the context of digitalization and "smart specialization" based on "smart" spatial benchmarking and impact investment directions.
\end{abstract}

Keywords: sustainable spatial development, "smart region", "smart specialization", human capital, digitalization, the concept of combined value, impact investment.

Acknowledgements: the study was carried out with the financial support of the Grant of the President of the Russian Federation (project number MC-23.2019.6). The title of the project - "'Smart Region' as an interdisciplinary concept of sustainable spatial development".

For citation: Lyshchikova J.V. 2021. Mechanisms of institutionalization and implementation of the concept of "Smart Region" in the management of sustainable spatial development of territories. Economics. Information technologies, 48 (2): 229-243. DOI 10.52575/2687-0932-2021-48-2-229-243.

\section{Введение}

Под влиянием глобальной синхронизации и конвергенции различных областей науки и технологий, перехода от индивидуального к сетевому и кластерному типам пространственного развития, повсеместного внедрения «умных решений» в мире сейчас происходит трансформация сложившейся ранее парадигмы устойчивого развития в «умное устойчивое развитие» (Smart Sustainable Development). Четвертая промышленная революция диктует концепцию Smart Sustainable Development [Girard, 2013; Martin, Evans, Karvonen, 2018], основанную на сквозных цифровых технологиях, инновациях и человеческом капитале. Цифровая трансформация предоставляет возможности инклюзивного экономического роста 
для отраслей, территорий и государств, одновременно порождая многочисленные вызовы, связанные с новыми формами взаимодействия экономики, общества и технологий.

Для терминологического описания цифровой трансформации пространственного развития и механизмов управления не только урбанизированными, но и сельскими территориями Северной Италии от Милана до долины реки По, в поисках нового взаимного равновесия между городом и регионом, европейским ученым-регионалистам потребовалось расширение теоретического справочного аппарата от концепции «умного города» до «умного города-региона», или просто до «умного региона». Европейский совет градостроителей (ЕСТР) предложил новое видение европейских городов в XXI веке, основанное на развитии полицентрических городских сетей, полностью безразличных к традиционным национальным и административными границам, в связи с чем «умный регион» может быть организован как местная полицентрическая городская сеть [Fernández Maldonado, 2012].

Рассматривая примеры успешных европейских «умных регионов», первыми следует упомянуть проекты Interreg (Bird, ICT4SMEs и LoG-IN), разработанные в период с 2002 по 2007 гг. городами и регионами североевропейских стран (Бельгия, Германия, Дания, Нидерланды, Швеция и Великобритания). Система пилотных проектов SmartRegions, курируемых с 2010 по 2013 год учреждениями, исследовательскими институтами и компаниями из восьми европейских стран (Финляндия, Норвегия, Германия, Австрия, Нидерланды, Польша, Румыния и Испания) в рамках программы Европейской комиссии «Интеллектуальная энергетика Европы» (IEE), создавалась с целью развития сетей знаний и достижения целевых показателей энергоэффективности Европы на 2016 и 2020 годы [Morandi, Rolando, Di Vita, 2016]. Объединяя четырнадцать соседних муниципалитетов, проект Comunità Montana Vallo di Diano (Италия) способствует развитию единой системы стратегирования, направленной на повышение мобильности ресурсов на местном уровне, экономической продуктивности, а также на переход к устойчивому управлению экологическими и человеческими ресурсами [Associazione, 2014; Morandi, Rolando, Di Vita, 2016]. Созданный шестью соседними муниципалитетами, проект Unione dei Comuni della Romagna Faentina (Италия) способствует развитию инклюзивного, «умного» и устойчивого сообщества. Он предполагает принятие плана по энергетике и окружающей среде, создание научно-технологического парка, обеспечение городских пространств бесплатным Wi-Fi, a также внедрение электронного управления на основе открытых данных (Associazione Nazionale Comuni Italiani, Osservatorio Nazionale Smart City 2014) [Associazione, 2014; Morandi, Rolando, Di Vita, 2016]. Проект Mantova Smart Region (Италия) запущен в 2012 году при содействии политехнического университета Милана. Его сущность заключается в экспериментальной интеграции цифровых инфраструктур и услуг с культурным, экологическим и ландшафтным наследием, а также во внедрении инновационного подхода к надмуниципальному управлению [Morandi, Rolando, Di Vita, 2016]. Таким образом, очевидно, что для европейских государств характерен так называемый трансграничный подход в формировании «умных регионов», что объясняется целенаправленной политикой государствчленов Европейского союза по обеспечению условий для трансграничного обмена информацией между странами и равного доступа к ней для всех граждан Европейского Союза на наднациональном уровне.

Индонезийский исследователь Сутриади [Sutriadi, 2018] определяет «умный регион» как новаторский подход к устойчивому планированию на региональном уровне, который способствует устойчивому развитию, основанному на знаниях, достигаемых посредством непрерывного обучения. Поскольку для Индонезии характерно сочетание городских агломераций и сельских территорий, в работе [Sutriadi, 2018] «умные территории» представлены в качестве иерархической технологической и инновационной концепции «умный город» - «умная деревня» - «умный регион» для достижения целей устойчивого развития. 
Российская научная академическая мысль и региональные управленческие практики развиваются в аналогичном ключе, формулируя основные положения и принципы формирования «умных регионов» как продолжение стратегий «умных городов». В частности, в работе [Кубрак, 2020] на основе систематизации результатов внедрения концепции «умный город» и лучших практик управления городской средой и пригородными территориями в рамках реализации национальных проектов «Жилье и комфортная городская среда», «Цифровая экономика Российской Федерации», «Экология» предлагается расширить концепцию «умный город» до концепции «умный регион». В исследовании [Тебекин, Егорова, 2019] на основе анализа динамики российских процессов урбанизации установлено, что значительная часть социально-экономических проблем развития территорий не может быть в полном объеме решена в рамках системы концепций «умный город» и должна решаться на других иерархических уровнях управления в рамках концепций «умный регион» и «умная страна».

Амбициозность утвержденного Правительством Российской Федерации национального проекта «Цифровая экономика» и анонсирование на высшем уровне старта реформы государственного управления диктуют требования к поиску новой модели регионального управления и устойчивого развития на основе комплексного внедрения цифровых технологий во все сферы функционирования экономики и общества. Подобные изменения уже активно происходят в большом числе регионов, что позволяет проанализировать и обобщить сложившиеся практики в рамках выявленных ранее подходов [Lyshchikova et al., 2019]. В настоящее время в двадцати субъектах РФ (в их числе Нижегородская область, Псковская область, Тюменская область, Приморский край, Ненецкий автономный округ) с 2018 года реализуются пилотные проекты в рамках соглашений регионов о сотрудничестве с ПАО «Ростелеком» в сфере реализации программы инновационного развития «Умный регион». Программа предполагает создание условий для внедрения в различные сферы деятельности регионов комплексных информационных решений, способствующих формированию современной инфокоммуникационной среды, развитию информационного общества, трансформации систем государственного и муниципального управления и интеграции их на базе платформенных решений, безопасному и комфортному проживанию на территории регионов, повышению качества жизни населения [В Нижегородской области...].

Нужно констатировать постепенное усиление и смещение акцента в российской практике от технократического подхода в сторону европейского комплексного (коэволюционного), основанного на «умной специализации», сквозных цифровых технологиях и развитии человеческого капитала. Это подтверждает тот факт, что в октябре 2019 года Совет по развитию цифровой экономики при Совете Федерации предложил создать в рамках национального проекта «Цифровая экономика РФ» новый федеральный проект «Цифровой регион», предполагающий создание информационных систем для решения задач всей территории регионов, в том числе сельских территорий. В марте 2020 года новую инициативу одобрил премьер-министр Михаил Мишустин, отметив необходимость консолидации бюджетов и синхронизации цифровых проектов в регионах, однако в июне 2020 года реализация проекта была отложена на вторую половину 2021 года в связи с перераспределением бюджетных средств на борьбу с коронавирусом. Следует согласиться, что существует определенная разрозненность цифровых инициатив в регионах наряду с дублированием и пересечением региональных и федеральных проектов. Например, Ульяновская и Свердловская области одновременно участвуют и в пилотных проектах ПАО «Ростелеком», и разработали и приняли собственные концепции [Концепция внедрения интеллектуальных цифровых технологий в Ульяновской области «Умный регион» на 20172030 годы; Концепция построения «Умного региона» на территории Свердловской области]. В то же время существует и запрос со стороны регионов, и накоплен необходимый человеческий потенциал и уровень развития цифровых и инновационных технологий, чтобы 
обеспечить максимальный социально-экономический и управленческий синергетический эффект от их внедрения.

\section{Объекты и методы исследования}

Целью исследования является разработка организационно-экономических механизмов институционализации и имплементации концепции «Умный регион» в управлении устойчивым пространственным развитием регионов России с учетом оценки человеческого капитала, в контексте цифровизации и «умной специализации».

Эмпирическую основу исследования составили данные статистического сборника Федеральной службы государственной статистики Российской Федерации [Регионы России, 2020], стратегические программные документы отдельных регионов Российской Федерации [Концепция внедрения интеллектуальных цифровых технологий в Ульяновской области «Умный регион» на 2017-2030 годы; Концепция построения «Умного региона» на территории Свердловской области; Паспорт региональной программы «Умная Кубань - лидеры будущего»; Стратегия социально-экономического развития Республики Татарстан до 2030 года], международные рейтинговые оценки цифровизации [Индекс готовности к сетевому обществу, 2020; Индекс развития в сфере ИКТ, 2017; Индекс цифровой экономики и общества, 2020; Индекс развития электронного правительства, 2020], материалы и выводы исследования Московской школы управления СКОЛКОВО [Цифровая жизнь российских регионов, 2020].

Результаты исследования получены с использованием программного аналитического продукта Deductor Academic. Для оценки и кластеризации регионов по выбранным в соответствии с методологией отбора показателей IRIS (Impact Reporting \& Investment Standards) показателям был сформирован набор данных, проведена оценка их качества, заполнение пропущенных данных (для двух показателей по Московской и Ленинградской области), редактирование выбросов и экстремальных значений (для г. Москва, г. СанктПетербург, отдельных показателей Московской и Ленинградской области), выявление дубликатов и противоречий. Далее была проведена кластеризация регионов Российской Федерации методом k-means, позволяющим самостоятельно установить число кластеров, и интерпретация полученных результатов.

\section{Результаты и их обсуждение}

Наряду с принципами «умной специализации» и внедрением на всех уровнях экономики и управления сквозных цифровых технологий, важнейшую роль в формировании «умного региона» играет качество человеческого капитала, социально-экономические эффекты приобретения и использования новых цифровых компетенций. Это подтверждается, например, выводами исследователей Московской школы управления СКОЛКОВО [Цифровая жизнь российских регионов, 2020], согласно которым критически важными для развития полноценной цифровой экосистемы оказались цифровые навыки и компетенции жителей тех или иных территорий. В связи с этим региональным администрациям, бизнес-лидерам и лидерам общественного мнения рекомендовано развивать цифровой спрос, формировать у населения навыки и компетенции в области эффективного использования цифровых платформ и систем, повышать качество человеческого капитала и творческую инновационную среду. При этом анализ комплексных изменений, происходящих в развитии человеческого капитала под воздействием цифровой трансформации экономики, по-прежнему представлен в современной научной литературе весьма фрагментарно [Чугреев, 2020; Кокуйцева, Шиманский, 2020; Васильев, 2020]; концепция расхождения и отставания развития человеческого капитала от экспонентного роста технико-технологической составляющей все еще находится на стадии разработки [Шелковников, Кузнецова, Петухова, Алексеев, 2019]. Наиболее полно оценка цифровизации человеческого капитала представлена в рейтингах цифрового развития, преимущественно международного уровня (табл. 1). 
Показатели оценки человеческого капитала в международных рейтингах цифровизации (составлено автором по [Индекс готовности к сетевому обществу, 2020; Индекс развития в сфере ИКТ, 2017; Индекс цифровой экономики и общества, 2020; Индекс развития электронного правительства, 2020]

Indicators of human capital assessment in international digitalization ratings (compiled by the author on [Networked Readiness Index, 2020; ICT Development Index, IDI, 2017; The Digital

Economy and Society Index, 2020; E-government Development Index, 2020]

\begin{tabular}{|c|c|c|c|c|}
\hline $\begin{array}{l}\text { № } \\
\text { ㅍ/II }\end{array}$ & Разработчик & $\begin{array}{c}\text { Наименование } \\
\text { рейтинга }\end{array}$ & $\begin{array}{l}\text { Наименование } \\
\text { индикатора }\end{array}$ & $\begin{array}{c}\text { Направления оценки } \\
\text { человеческого капитала }\end{array}$ \\
\hline 1. & $\begin{array}{l}\text { Всемирный } \\
\text { экономический } \\
\text { форум (The World } \\
\text { Economic Forum) }\end{array}$ & $\begin{array}{l}\text { Индекс } \\
\text { готовности к } \\
\text { сетевому } \\
\text { обществу } \\
\text { (Networked } \\
\text { Readiness Index) }\end{array}$ & «Люди» (People) & $\begin{array}{l}\text { Использование Интернет, } \\
\text { мобильной } \\
\text { широкополосной связи, } \\
\text { виртуальных социальных } \\
\text { сетей, зачисление в вузы, } \\
\text { уровень грамотности } \\
\text { взрослого населения, } \\
\text { навыки в области ИКТ }\end{array}$ \\
\hline 2. & $\begin{array}{l}\text { Международный } \\
\text { союз электросвязи } \\
\text { (International } \\
\text { Telecommunication } \\
\text { Union, ITU) }\end{array}$ & $\begin{array}{l}\text { Индекс развития в } \\
\text { сфере ИКТ (ICT } \\
\text { Development } \\
\text { Index, IDI) }\end{array}$ & $\begin{array}{l}\text { Использование } \\
\text { ИКТ, навыки } \\
\text { населения в } \\
\text { сфере ИКТ }\end{array}$ & $\begin{array}{l}\text { Использование Интернет, } \\
\text { фиксированный } \\
\text { широкополосный и } \\
\text { мобильный } \\
\text { широкополосный доступ }\end{array}$ \\
\hline 3. & $\begin{array}{l}\text { Европейская } \\
\text { комиссия (European } \\
\text { Commission) }\end{array}$ & $\begin{array}{l}\text { Индекс цифровой } \\
\text { экономики и } \\
\text { общества (The } \\
\text { Digital Economy } \\
\text { and Society Index, } \\
\text { DESI) }\end{array}$ & $\begin{array}{l}\text { Человеческий } \\
\text { капитал/ } \\
\text { Цифровые } \\
\text { навыки }\end{array}$ & $\begin{array}{l}\text { Базовые цифровые навыки } \\
\text { и навыки работы с } \\
\text { программным } \\
\text { обеспечением, } \\
\text { специалисты в области } \\
\text { ИКТ, в том числе } \\
\text { женщины, выпускники в } \\
\text { сфере ИКТ }\end{array}$ \\
\hline 4. & $\begin{array}{l}\text { Организация } \\
\text { объединенных наций } \\
\text { (The United Nations, } \\
\text { UN) }\end{array}$ & $\begin{array}{l}\text { Индекс развития } \\
\text { электронного } \\
\text { правительства } \\
\text { (E-government } \\
\text { Development } \\
\text { Index) }\end{array}$ & $\begin{array}{l}\text { Индекс } \\
\text { человеческого } \\
\text { капитала }\end{array}$ & $\begin{array}{l}\text { Уровень грамотности } \\
\text { взрослого населения, } \\
\text { совокупный валовой } \\
\text { коэффициент охвата } \\
\text { начальным, средним и } \\
\text { высшим образованием, } \\
\text { ожидаемая } \\
\text { продолжительность } \\
\text { обучения, средняя } \\
\text { продолжительность } \\
\text { обучения }\end{array}$ \\
\hline
\end{tabular}

Каждый из рассматриваемых индексов представлен собственной методологией оценки и широким набором показателей, исходя из возможностей и данных международной статистики. Общим является подход, согласно которому оценка человеческого капитала происходит, исходя из наличия доступной ИКТ-инфраструктуры, готовности людей использовать ИКТ (наличие компетенций), интенсивности использования ИКТ обществом и воздействия ИКТ, т. е. измерения социально-экономического эффекта от их внедрения.

Исходя из этого, считаем возможным предложить инструментарий исследования человеческого капитала региона в контексте цифровизации на основе концепции комбинированной стоимости и соответствующей ей методологии отбора показателей IRIS 
(Impact Reporting \& Investment Standards). Комбинированная (смешанная) стоимость является одной из ключевых категорий в сфере «инвестиций, содействующих преобразованию общества» (impact investment). Она предполагает комплексный подход к измерению стоимости (ценности) не только с экономической, но и социальной и экологической точки зрения. Основным классификационным инструментом импакт-инвестирования является матрица, представляющая собой таблицу $3 \times 3$, основанную на ранее разработанной концепции тройного критерия (Triple bottom line, TBL или 3BL): планета, люди, прибыль, выведенной в 1994 году американским экономистом и предпринимателем Джоном Элкингтоном. Однако основной трудностью при использовании концепции комбинированной стоимости в оценке экономических, социальных и экологических эффектов инвестирования по-прежнему остается подбор индикаторов [Lyshchikova, Dobrodomova, Huseynova, 2020].

Показатели IRIS изначально разрабатывались для сообщества сферы «импактинвестиций», но сейчас они находят все более широкое применение, например, в организациях, которые стремятся измерить социальную ценность, возникающую в процессе их деятельности. Каталог IRIS в настоящее время включает 488 показателей (при этом число показателей постоянно увеличивается), распределенных по пяти разделам: финансовая эффективность; операционные результаты; эффект от использования; описание продукта; описание организации. Разделы «Описание организации» (Organization Description) и «Описание продукта» (Product Description) включают информацию общего характера, которая объединена в концепции измерения комбинированной стоимости под названием «Входные данные и ключевые виды деятельности (Input and key activities)». Что касается других разделов, то финансовая эффективность характеризуется в методологии IRIS традиционными показателями изменения финансовых характеристик организации (выручка, прибыль и т. д.), показатели операционных результатов включают опосредованные положительные эффекты инвестиций для организации, например, прирост числа рабочих мест организации, снижение количества несчастных случаев, травм и ущерба здоровью на рабочем месте, снижение текучести кадров, динамику затрат организации на оплату труда, участие сотрудников в профессиональном обучении и т. д. Показатели эффекта от использования продукта могут включать широкий спектр социальных и экологических положительных эффектов, касающихся уже не организации, а общества в целом (посещаемость школ и образовательные программы, площадь территорий под лесными массивами, оказание услуг в сфере здравоохранения, инвестиции в жилищную сферу, экономия водных ресурсов, сокращение выбросов парниковых газов и вредных отходов и т. д.).

Таким образом, исходя из методологии оценки человеческого капитала, используемой в международных индексах цифровизации, концепции комбинированной стоимости и соответствующей ей методологии отбора показателей IRIS (Impact Reporting \& Investment Standards) и с учетом ограничений российской статистики, нами предложена система показателей оценки человеческого капитала на региональном уровне, период исследования 2019 год (табл. 2).

C использованием программного аналитического продукта Deductor Academic проведена оценка и кластеризация регионов РФ согласно четырем группам показателей цифровизации человеческого капитала методом k-means (таблица 3).

Результаты кластеризации позволяют сделать ряд промежуточных выводов, характеризующих пространственные особенности цифровизации человеческого капитала регионов России. В кластер с высоким уровнем цифровизации человеческого капитала по всем четырем группам рассматриваемых показателей вошел только город Москва. Поскольку первая группа показателей характеризует развитие цифровой инфраструктуры в регионе, вторая - степень готовности жителей использовать ИКТ, третья и четвертая - интенсивность внедрения ИКТ в хозяйственную деятельность и создание ценности, можно утверждать, что наиболее сбалансированно данные процессы протекают только в г. Москве. Остальные же представленные регионы характеризуются дисбалансами (цифровыми «разрывами») разной 
степени в развитии ИКТ инфраструктуры (Воронежская область, Краснодарский край, Красноярский край, Нижегородская область, Пермский край, Республика Башкортостан, Республика Крым, Северная Осетия-Алания, Тамбовская область), готовности населения региона к использованию ИКТ (г. Севастополь, Республика Крым), внедрении цифровых технологий в деятельность предприятий (Республика Дагестан, Северная Осетия-Алания, Чеченская Республика), воздействии ИКТ на создание ценности (Белгородская область, Воронежская область, г. Севастополь, Курская область, Липецкая область, Республика Дагестан, Республика Крым, Северная Осетия-Алания, Тамбовская область, Чеченская Республика).

Таблица 2

Table 2

Система показателей оценки регионального человеческого капитала в контексте цифровизации

The system of indicators for assessing regional human capital in the context of digitalization

\begin{tabular}{|c|c|c|c|}
\hline $\begin{array}{c}\text { Группа показателей } \\
\text { по методологии } \\
\text { международных } \\
\text { рейтингов }\end{array}$ & $\begin{array}{c}\text { Группа } \\
\text { показателей по } \\
\text { методологии IRIS }\end{array}$ & $\begin{array}{l}\text { Наименование } \\
\text { показателя }\end{array}$ & $\begin{array}{l}\text { Единицы } \\
\text { измерения }\end{array}$ \\
\hline \multirow[t]{2}{*}{$\begin{array}{l}\text { Наличие доступной } \\
\text { ИКТ-инфраструктуры }\end{array}$} & \multirow{2}{*}{$\begin{array}{l}\text { Входные данные и } \\
\text { ключевые } \quad \text { виды } \\
\text { деятельности (Input } \\
\text { and key activities) }\end{array}$} & $\begin{array}{l}\text { Затраты на внедрение и } \\
\text { использование цифровых } \\
\text { технологий }\end{array}$ & млн. руб. \\
\hline & & 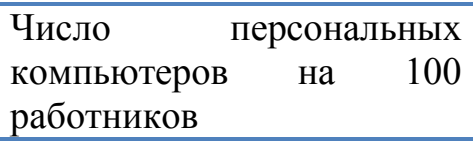 & единиц \\
\hline \multirow[t]{2}{*}{$\begin{array}{l}\text { Готовность людей } \\
\text { использовать ИКТ }\end{array}$} & \multirow[t]{2}{*}{ Результат (Output) } & $\begin{array}{l}\text { Использование } \\
\text { Интернет населением }\end{array}$ & $\begin{array}{l}\text { \% от общей } \\
\text { численности } \\
\text { населения субъекта } \\
\text { РФ }\end{array}$ \\
\hline & & $\begin{array}{l}\text { Число подключенных } \\
\text { абонентских устройств } \\
\text { мобильной связи на } 1000 \\
\text { человек населения }\end{array}$ & единиц \\
\hline $\begin{array}{l}\text { Интенсивность } \\
\text { использования ИКТ } \\
\text { обществом }\end{array}$ & $\begin{array}{l}\text { Эффект, } \\
\text { (Impact) }\end{array}$ & $\begin{array}{l}\text { Использование } \\
\text { специальных программных } \\
\text { средств и «облачных» } \\
\text { сервисов в организациях }\end{array}$ & $\begin{array}{l}\text { \% от числа } \\
\text { обследованных } \\
\text { организаций } \\
\text { субъекта РФ }\end{array}$ \\
\hline Воздействие ИКТ & $\begin{array}{l}\text { Создание ценности } \\
\text { (Value creation) }\end{array}$ & $\begin{array}{lr}\text { Объем } & \text { информации, } \\
\text { переданной при доступе к } \\
\text { сети } \\
\text { фиксированного } \\
\text { мобильного доступа }\end{array}$ & петабайт \\
\hline
\end{tabular}

Дискуссионными вопросами методики, требующими дальнейшего обоснования, разработки, и, возможно, уточнения и корректировки, по нашему мнению, являются:

- структура, количество и иерархия шагов в цепочке движения от вложения ресурсов к эффекту, поскольку в различных источниках можно встретить разнообразные определения элементов цепочки результатов в связи с тем, что это переводные термины, и даже профессиональное сообщество импакт-инвесторов еще не выработало окончательный общепринятый глоссарий;

- формирование самого набора показателей, в значительной степени определяемого ограниченностью российской региональной статистики в сфере цифровизации и развития ИКТ; 
- необходимость использования при оценке абсолютных значений за период времени или показателей динамики, учета временного лага для показателей эффекта и создания ценности и определения величины этого временного лага.

Таблица 3

Table 3

Результаты кластеризации регионов Российской Федерации по показателям цифровизации человеческого капитала за 2019 год

(рассчитано автором на основе [Регионы России, 2020], представлены выборочно) Results of clustering of regions of the Russian Federation on indicators of digitalization of human capital for 2019

(calculated by the author based on [Regions of Russia, 2020], presented selectively)

\begin{tabular}{|c|c|c|c|}
\hline $\begin{array}{c}\text { Группа } \\
\text { показателей } \\
1\end{array}$ & $\begin{array}{c}\text { Кластер } 1 \text { (высокий } \\
\text { уровень) } \\
2\end{array}$ & $\begin{array}{c}\text { Кластер } 2 \text { (средний } \\
\text { уровень) } \\
3\end{array}$ & $\begin{array}{c}\text { Кластер } 3 \text { (низкий } \\
\text { уровень) } \\
4\end{array}$ \\
\hline $\begin{array}{l}\text { Входные } \\
\text { данные } \\
\text { ключевые виды } \\
\text { деятельности } \\
\text { (Input and key } \\
\text { activities) }\end{array}$ & $\begin{array}{c}\text { г. Москва, г. Санкт- } \\
\text { Петербург, } \\
\text { г. Севастополь, } \\
\text { Новосибирская область, } \\
\text { Республика Татарстан, }\end{array}$ & $\begin{array}{c}\text { Белгородская } \\
\text { область, } \\
\text { Кемеровская } \\
\text { область, Курская } \\
\text { область, Липецкая } \\
\text { область, Республика } \\
\text { Дагестан, Чеченская } \\
\text { Республика }\end{array}$ & $\begin{array}{c}\text { Воронежская область, } \\
\text { Краснодарский край, } \\
\text { Красноярский край, } \\
\text { Нижегородская } \\
\text { область, Пермский } \\
\text { край, Республика } \\
\text { Башкортостан, } \\
\text { Республика Крым, } \\
\text { Северная Осетия- } \\
\text { Алания, Тамбовская } \\
\text { область }\end{array}$ \\
\hline $\begin{array}{l}\text { Результат } \\
\text { (Output) }\end{array}$ & $\begin{array}{c}\text { Воронежская область, } \\
\text { г. Москва, г. Санкт- } \\
\text { Петербург, Курская } \\
\text { область, Нижегородская } \\
\text { область, Новосибирская } \\
\text { область, Республика } \\
\text { Башкортостан, } \\
\text { Республика Дагестан, } \\
\text { Республика Татарстан, } \\
\text { Северная Осетия- } \\
\text { Алания, Чеченская } \\
\text { Республика }\end{array}$ & $\begin{array}{c}\text { Белгородская } \\
\text { область, } \\
\text { Кемеровская } \\
\text { область, } \\
\text { Краснодарский } \\
\text { край, Красноярский } \\
\text { край, Липецкая } \\
\text { область, Пермский } \\
\text { край, Тамбовская } \\
\text { область }\end{array}$ & $\begin{array}{c}\text { г. Севастополь, } \\
\text { Республика Крым }\end{array}$ \\
\hline $\begin{array}{l}\text { Эффект, } \\
\text { влияние } \\
\text { (Impact) }\end{array}$ & $\begin{array}{c}\text { Белгородская область, } \\
\text { г. Москва, г. Санкт- } \\
\text { Петербург, } \\
\text { г. Севастополь, Курская } \\
\text { область, Липецкая } \\
\text { область, Новосибирская } \\
\text { область, Пермский край, } \\
\text { Республика Крым, } \\
\text { Республика Татарстан, } \\
\text { Тамбовская область }\end{array}$ & $\begin{array}{c}\text { Воронежская } \\
\text { область, } \\
\text { Кемеровская } \\
\text { область, } \\
\text { Краснодарский } \\
\text { край, Красноярский } \\
\text { край, } \\
\text { Нижегородская } \\
\text { область, Республика } \\
\text { Башкортостан }\end{array}$ & $\begin{array}{c}\text { Республика Дагестан, } \\
\text { Северная Осетия- } \\
\text { Алания, Чеченская } \\
\text { Республика }\end{array}$ \\
\hline
\end{tabular}


Окончание табл. 3

\begin{tabular}{lccc|}
\multicolumn{1}{c}{1} & \multicolumn{2}{c}{3} & 4 \\
Создание & г. & г. Санкт-Петербург, & Белгородская область, \\
ценности & Москва & Кемеровская область, & Воронежская область, \\
(Value & & Краснодарский край, & г. Севастополь, Курская область, \\
creation) & & Красноярский край, & Липецкая область, Республика \\
& & Нижегородская область, & Дагестан, Республика Крым, \\
& & Новосибирская область, & Северная Осетия-Алания, \\
& Пермский край, Республика & Тамбовская область, Чеченская \\
& Башкортостан, Республика & Республика \\
& Татарстан & \\
& &
\end{tabular}

Выявленные в результате кластеризации пространственные особенности цифровизации человеческого капитала регионов могут быть использованы для формирования системы критериальных признаков и многомерной типологии регионов России согласно приоритетным направлениям «умной специализации» и развитию человеческого капитала путем построения управленческой матрицы позиционирования регионов в целях внедрения концепции «Умный регион», состоящей из девяти ячеек, в которой по одной оси представлены направления «умной специализации» региона (локальная, национальная и глобальная специализация), а по другой уровень цифровизации человеческого капитала региона (табл. 4).

Таблица 4

Table 4

Шаблон управленческой матрицы позиционирования регионов в целях внедрения концепции «Умный регион»

Template of the management matrix for positioning regions in order to implement the concept of "Smart Region"

\begin{tabular}{|c|c|c|c|c|}
\hline \multirow{3}{*}{$\begin{array}{c}\text { уровень } \\
\text { цифровизации } \\
\text { человеческого } \\
\text { капитала } \\
\text { региона }\end{array}$} & высокий & $\begin{array}{c}\text { Регион } 1 \\
\ldots \\
\text { Регион i } \\
\end{array}$ & $\begin{array}{c}\text { Регион } 2 \\
\ldots \\
\text { Регион ј } \\
\end{array}$ & $\begin{array}{c}\text { Регион } 3 \\
\ldots \\
\text { Регион k } \\
\end{array}$ \\
\hline & средний & $\begin{array}{c}\text { Регион } 4 \\
\ldots \\
\text { Регион } 1 \\
\end{array}$ & $\begin{array}{c}\text { Регион } 5 \\
\ldots \\
\text { Регион m } \\
\end{array}$ & $\begin{array}{c}\text { Регион } 6 \\
\ldots \\
\text { Регион n } \\
\end{array}$ \\
\hline & низкий & $\begin{array}{c}\text { Регион } 7 \\
\ldots \\
\text { Регион p } \\
\end{array}$ & $\begin{array}{c}\text { Регион } 8 \\
\ldots \\
\text { Регион r } \\
\end{array}$ & $\begin{array}{c}\text { Регион } 9 \\
\ldots \\
\text { Регион t } \\
\end{array}$ \\
\hline \multirow{2}{*}{\multicolumn{2}{|c|}{ Критерии типологии }} & локальная & национальная & глобальная \\
\hline & & \multicolumn{3}{|c|}{ направления «умной специализации» региона } \\
\hline
\end{tabular}

Для преодоления выявленных в результате кластеризации «цифровых разрывов» и обеспечения перехода от текущей к перспективной региональной «умной специализации» [Стрябкова, Лыщикова, 2019] необходимо дифференцированное в зависимости от уровня цифровизации человеческого капитала регионов внедрение механизмов его воспроизводства на основе «умного» пространственного бенчмаркинга (заимствование и использование лучших практик аналогичных по уровню и проблематике развития регионов) [Дубровская, Кудрявцева, Козоногова, 2018] и направлений импакт-инвестирования [Lyshchikova, Dobrodomova, Huseynova, 2020] (рис. 1).

При этом развивающее импакт-инвестирование предполагает реализацию мероприятий по развитию региональной инфраструктуры и созданию региональных механизмов в новых сферах и объектах инвестирования с целью разрешения экономических, социальных и экологических проблем с участием всех стейкхолдеров; локализующее импакт- 
инвестирование - мероприятия, направленные на популяризацию новой парадигмы устойчивого пространственного развития, консалтинг, исследование и развитие инструментов и моделей построения «умного региона»; обуславливающее импакт-инвестирование мероприятия по обеспечению доступа инвесторов к новым сферам деятельности региона путем формирования новых моделей, технологий и стандартов ведения бизнеса.

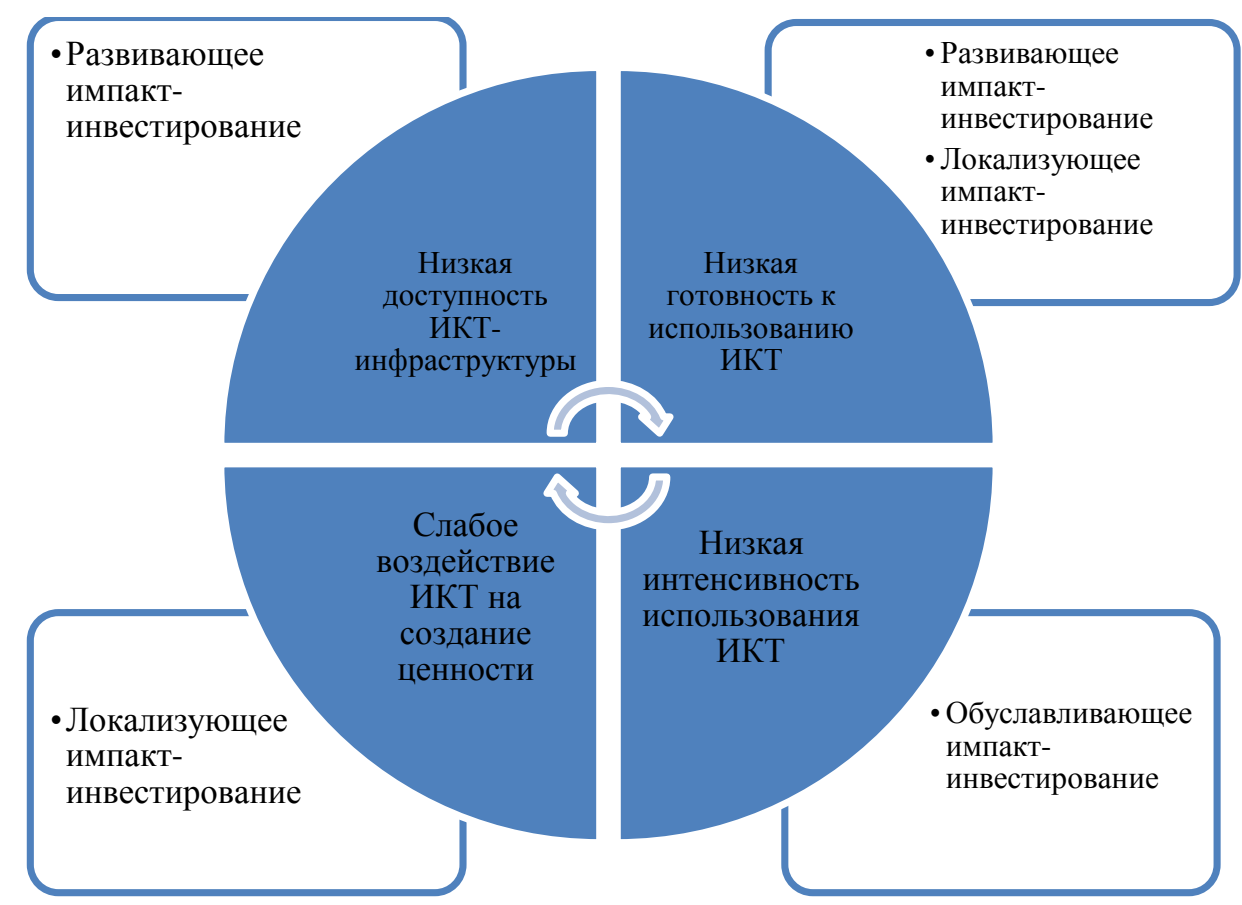

Рис. 1. Направления импакт-инвестирования для преодоления «цифровых разрывов» в развитии человеческого капитала региона

Fig. 1. Directions of impact investment to overcome the "digital gaps" in the development of human capital in the region

В завершение представим этапы реализации, инструментарий и последовательность процедур внедрения концепции «Умный регион» в управление устойчивым пространственным развитием территорий в виде алгоритма, включающего определение стратегических приоритетов текущей и перспективной «умной специализации» региона на межрегиональном, национальном и глобальном уровне, оценку уровня цифровизации человеческого капитала региона, и, на основании полученных результатов, формирование механизмов институционализации и имплементации концепции «Умный регион» в управлении устойчивым пространственным развитием (рис. 2).

\section{Заключение}

Таким образом, успешная имплементация концепции «Умный регион» на основе предложенных инструментов и механизмов будет способствовать эффективному развитию отраслей «умной специализации» региональной экономики, подкрепленных соответствующими технологиями, и цифровых компетенций регионального человеческого капитала, что может индуцировать ряд положительных эффектов в контексте достижения целей устойчивого развития. Можно выделить такие потенциальные эффекты внедрения «умного региона» в парадигме Smart Sustainable Development, как: 


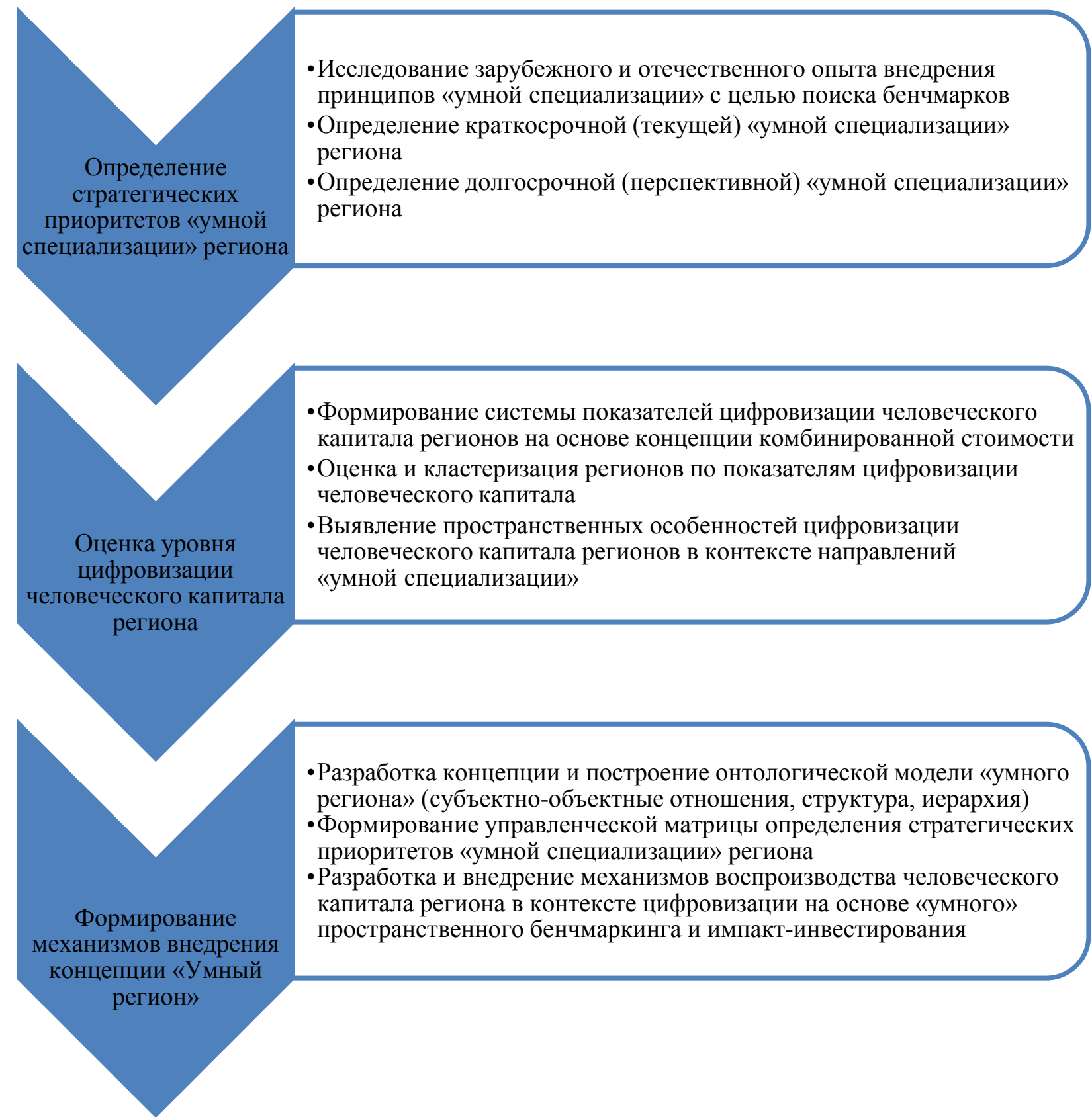

Рис. 2. Алгоритм внедрения концепции «Умный регион» в управление устойчивым пространственным развитием территорий

Fig. 2. Algorithm for implementing the concept of "Smart Region" in the management of sustainable spatial development of territories

- обеспечение целостности регионального сообщества за счет создания условий для развития человеческого и социального капитала и содействия изменениям для достижения лучшего качества жизни граждан;

- сохранение локальной истории и культуры, «неявного знания» как фактора наукоемкого инновационного развития в концепции «умной специализации»;

- усиление пространственной связности урбанизированных и сельских территорий в контексте интеграции и формирования единого национального пространства;

- диверсифицированная эволюция отраслевой структуры региональной экономики, от первичного до третичного и «четвертого» сектора (экономики знаний) на основе принципов «умной специализации»; 
- формирование и развитие технологической и цифровой компетентности региональных и муниципальных органов власти, университетов и научно-исследовательских центров;

- замещение некоторой части региональных физических потоков виртуальными потоками путем построения и использования «цифровых двойников регионов»;

- рост устойчивости и конкурентоспособности региона благодаря формированию и развитию синергии между физической и цифровой инфраструктурой;

- повышение эффективности сотрудничества и согласования коллективных интересов региональных стейкхолдеров.

При этом внедрение концепции «умного региона» в обязательном порядке должно учитывать уровень и особенности развития того или иного субъекта, такие как региональная (локальная) история и культура, пространственный контекст и ограничения городского и регионального планирования, доминирующие и перспективные отрасли экономики, степень развития инновационной и цифровой инфраструктуры, технологическая (цифровая) готовность органов власти и населения.

\section{Список источников}

1. В Нижегородской области будут развивать проект «Умный регион». URL: https://www.rbc.ru/nn/20/04/2018/5ad9ba6f9a794723c5faca44 (дата обращения: 27.11.2020)

2. Индекс готовности к сетевому обществу. 2020. URL: https://networkreadinessindex.org/ (дата обращения: 27.11.2020)

3. Индекс развития в сфере ИКТ. 2017. URL: https://www.itu.int/en/ITUD/Statistics/Pages/publications/mis2017/methodology.aspx (дата обращения: 27.11.2020)

4. Индекс развития электронного правительства. 2020. URL: https://www.un.org/ development/desa/publications/publication/2020-united-nations-e-government-survey (дата обращения: 27.11.2020).

5. Индекс цифровой экономики и общества. 2020. URL: https:/ec.europa.eu/digital-singlemarket/en/digital-economy-and-society-index-desi (дата обращения: 27.11.2020).

6. Концепция внедрения интеллектуальных цифровых технологий в Ульяновской области «Умный регион» на 2017-2030 годы. URL: https://it-fund73.ru/ulsmartregion/Koncept.php (дата обращения: 27.11.2020)

7. Концепция построения «Умного региона» на территории Свердловской области. URL: https://dis.midural.ru/article/show/id/1241 (дата обращения: 27.11.2020)

8. Паспорт региональной программы «Умная Кубань - лидеры будущего». URL: https://economy.krasnodar.ru/strategic-planning/files/Pasport_FP_Umnaia_Kuban.pdf (дата обращения: 27.11.2020)

9. Регионы России. Социально-экономические показатели. 2020: Стат. сб. / Росстат. М., 1242 с.

10.Стратегия социально-экономического развития Республики Татарстан до 2030 года. URL: http://docs2.cntd.ru/document/428570021 (дата обращения: 27.11.2020).

11.Цифровая жизнь российских регионов. Московская школа управления СКОЛКОВО, 2020. URL: https://www.skolkovo.ru/researches/digital-life-of-russian-cities/ (дата обращения: 27.11.2020).

\section{Список литературы}

1. Васильев В.А. 2020. Механизм формирования человеческого капитала в условиях цифровизации. Экономика. Бизнес. Банки, 10 (48): 60-68.

2. Дубровская Ю.В., Кудрявцева М.Р., Козоногова Е.В. 2018. «Умный» бенчмаркинг как основа стратегического планирования регионального развития. Экономические и социальные перемены: факты, тенденции, прогноз, 11(3): 100-116. DOI 10.15838/esc.2018.3.57.7

3. Кокуйцева Т.В., Шиманский А.А. 2020. Теоретические основы формирования и развития человеческого капитала в российской и зарубежной литературе. Вопросы инновационной экономики, 10(1): 233-248. 
4. Кубрак И.А. 2020. От реализации концепции «умный город»к внедрению концепции «умный регион» как одному из направлений совершенствования регионального управления. Вестник Российского нового университета. Серия: Человек и общество, 3: 57-64.

5. Стрябкова Е.А., Лыщикова Ю.В. 2019. Развитие методических подходов к определению приоритетов «умной специализации» территорий. Экономика: вчера, сегодня, завтра, 9(12A): 73-82. DOI10.34670/AR.2020.92.12.037

6. Тебекин А.В., Егорова А.А. 2019. Решение социальных проблем городов с помощью технологий «умный город»: проблемы и перспективы. Журнал социологических исследований, 4(4): 32-46.

7. Чугреев А.С. 2020. Роль человеческого капитала в условиях развития цифровой экономики региона. Московский экономический журнал, 7: 153-162.

8. Шелковников С.А., Кузнецова И.Г., Петухова М.С., Алексеев А.А. 2019. Цифровизация как тренд развития сельского хозяйства в условиях нового технологического уклада. Вестник Забайкальского государственного университета, 25(8): 119-126.

9. Associazione Nazionale Comuni Italiani, Osservatorio Nazionale Smart City. 2014. Vademecum per la città intelligente. URL: http://osservatoriosmartcity.it/il-vademecum/ (дата обращения: 27.11.2020).

10.Chris J. Martin, James Evans, Andrew Karvonen. Smart and sustainable? Five tensions in the visions and practices of the smart-sustainable city in Europe and North America. 2018. Technological Forecasting and Social Change, 133: 269-278. https://doi.org/10.1016/j.techfore.2018.01.005

11.Fernández Maldonado, A.M. 2012. ICT and spatial planning in European Cities. Reviewing the New Charter of Athens. Built Environment, 38(4): 93-103.

12.Luigi Fusco Girard. 2013. Toward a Smart Sustainable Development of Port Cities/Areas: The Role of the "Historic Urban Landscape" Approach. Sustainability, 5: 4329-4348. DOI10.3390/su5104329

13.Lyshchikova J.V., Dobrodomova T.N., Huseynova Vafa Arif. 2020. Impact investment: a smart strategy for sustainable development goals achievement. Economic and Social Development (Book of Proceedings Vol. 1/4), 55th International Scientific Conference on Economic and Social Development, 761-769.

14.Lyshchikova J.V., Stryabkova E.A., Glotova A.S., Dobrodomova T.N. 2019. The 'Smart Region' concept: the implementation of digital technology. Journal of Advanced Research in Law and Economics, 10, 4 (42): 1338-1345.

15.Morandi C., Rolando A., Di Vita S. 2016. From Smart City to Smart Region: Digital Services for an Internet of Places. Springer, $103 \mathrm{p}$.

16.Rolando A., Djordjevic T. 2013. Learning from places: ICTs for EXPO 2015 in the Turin-Milan region. The Journal of Urbanism. NUL-New Urban Languages conference proceedings (Milan, 19-21 June 2013), 27: 70-78.

17.Sutriadi R. 2018. Defining smart city, smart region, smart village, and technopolis as an innovative concept in Indonesia's urban and regional development themes to reach sustainability. IOP Conference Series: Earth and Environmental Science: 105-115. DOI10.1088/1755-1315/202/1/012047.

\section{References}

1. Vasiliev V.A. 2020. The mechanism of human capital formation in the context of digitalization. Economy. Business. Banks, 10 (48): 60-68 (in Russian).

2. Dubrovskaya Yu.V., Kudryavtseva M.R., Kozonogova E.V. 2018. "Smart" benchmarking as a basis for strategic planning in regional development. Economic and Social Changes: Facts, Trends, Forecast, 11(3): 100-116. DOI 10.15838/esc.2018.3.57.7 (in Russian).

3. Kokuitseva T.V., Shimansky A.A. 2020. Theoretical foundations of the formation and development of human capital in Russian and foreign literature. Questions of Innovative Economy, 10 (1): 233-248 (in Russian).

4. Kubrak I.A. 2020. From the implementation of the "smart city" concept to the implementation of the "smart region" concept as one of the directions for improving regional management. Bulletin of the Russian New University. Series: Man and Society, 3: 57-64 (in Russian).

5. Stryabkova E.A., Lyshchikova Yu.V. 2019. Razvitie metodicheskih podhodov k opredeleniyu prioritetov «umnoj specializacii» territorij [Development of methodological approaches to determining priorities of "smart specialization" of territories]. Ekonomika: vchera, segodnya, zavtra, 9 (12A): 73-82. DOI10.34670/AR.2020.92.12.037 (in Russian). 
6. Tebekin A.V., Egorova A.A. 2019. Solving social problems of cities with the help of "smart city" technologies: problems and prospects. Journal of Sociological Research, 4 (4): 32-46 (in Russian).

7. Chugreev A.S. 2020. The role of human capital in the development of the digital economy of the region. Moscow Economic Journal, 7: 153-162 (in Russian).

8. Shelkovnikov S.A., Kuznetsova I.G., Petukhova M.S., Alekseev A.A. 2019. Digitalization as a trend in the development of agriculture in the context of a new technological order. Bulletin of the TransBaikal State University, 25 (8): 119-126 (in Russian).

9. Associazione Nazionale Comuni Italiani, Osservatorio Nazionale Smart City. 2014. Vademecum per la città intelligente. URL: http://osservatoriosmartcity.it/il-vademecum/ (date of request: 27.11.2020).

10.Chris J. Martin, James Evans, Andrew Karvonen. Smart and sustainable? Five tensions in the visions and practices of the smart-sustainable city in Europe and North America. 2018. Technological Forecasting and Social Change, 133: 269-278. https://doi.org/10.1016/j.techfore.2018.01.005

11.Fernández Maldonado, A.M. 2012. ICT and spatial planning in European Cities. Reviewing the New Charter of Athens. Built Environment, 38 (4): 93-103.

12.Luigi Fusco Girard. 2013. Toward a Smart Sustainable Development of Port Cities/Areas: The Role of the "Historic Urban Landscape" Approach. Sustainability, 5: 4329-4348. DOI10.3390/su5104329

13.Lyshchikova J.V., Dobrodomova T.N., Huseynova Vafa Arif. 2020. Impact investment: a smart strategy for sustainable development goals achievement. Economic and Social Development (Book of Proceedings Vol. 1/4), 55th International Scientific Conference on Economic and Social Development, 761-769.

14.Lyshchikova J.V., Stryabkova E.A., Glotova A.S., Dobrodomova T.N. 2019. The 'Smart Region' concept: the implementation of digital technology. Journal of Advanced Research in Law and Economics, 10, 4 (42): 1338-1345.

15.Morandi C., Rolando A., Di Vita S. 2016. From Smart City to Smart Region: Digital Services for an Internet of Places. Springer, $103 \mathrm{p}$.

16.Rolando, A., Djordjevic, T. 2013. Learning from places: ICTs for EXPO 2015 in the Turin-Milan region. The Journal of Urbanism. NUL-New Urban Languages conference proceedings (Milan, 19-21 June 2013), 27: 70-78.

17.Sutriadi, R. 2018. Defining smart city, smart region, smart village, and technopolis as an innovative concept in Indonesia's urban and regional development themes to reach sustainability. IOP Conference Series: Earth and Environmental Science: 105-115. DOI10.1088/1755-1315/202/1/012047.

\section{ИНФОРМАЦИЯ ОБ АВТОРЕ}

Лыщикова Юлия Владимировна, кандидат экономических наук, доцент, доцент кафедры прикладной экономики и экономической безопасности Белгородского государственного национального исследовательского университета, г. Белгород, Россия

\section{INFORMATION ABOUT THE AUTHOR}

Julia V. Lyshchikova, Candidate of Economic Sciences, Associate Professor, Associate Professor of the Department of Applied Economics and Economic Security, Belgorod National Research University, Belgorod, Russia 